\title{
Pharmaceutical versus mechanical induction of labor
}

\author{
Malak Alsaif $^{1 *}$, Nayel Helmy ${ }^{2}$, Fatimah Almuallem ${ }^{3}$, Shahad Almagboul ${ }^{3}$, Hilyil Almtrafi ${ }^{4}$, \\ Bashaer Matouq ${ }^{5}$, Nawfal Alsufayan ${ }^{5}$, Ruba Saleh $^{6}$, Sultan Aldalbahi ${ }^{7}$, Afnan Alshahrani ${ }^{8}$
}

${ }^{1}$ College of Medicine, King Saud bin Abdulaziz University for Health Sciences, Riyadh, Saudi Arabia

${ }^{2}$ Department of Obstetrics and Gynecology, Etoile First Clinic, Jeddah, Saudi Arabia

${ }^{3}$ College of Medicine, Umm Al-Qura University, Mecca, Saudi Arabia

${ }^{4}$ Quality of Medicine, Advanced International Pharmaceutical Company (AIPCO), Jeddah, Saudi Arabia

${ }^{5}$ College of Medicine, Batterjee Medical College, Jeddah, Saudi Arabia

${ }^{6}$ College of Medicine, Ibn Sina National College, Jeddah, Saudi Arabia

${ }^{7}$ Department of Pharmacy, King Abdulaziz University Hospital, Jeddah, Saudi Arabia

${ }^{8}$ Department of Pharmacy, Southern Region Armed Forces Hospital, Khamis Mushait, Saudi Arabia

Received: 04 September 2018

Accepted: 10 September 2018

\author{
*Correspondence: \\ Dr. Malak Alsaif, \\ E-mail: malak.alsaif@gmail.com
}

Copyright: () the author(s), publisher and licensee Medip Academy. This is an open-access article distributed under the terms of the Creative Commons Attribution Non-Commercial License, which permits unrestricted non-commercial use, distribution, and reproduction in any medium, provided the original work is properly cited.

\begin{abstract}
Labor induction is one of the most common obstetric interventions carried out in obstetric institutions. More than one fifth of labors needs induction. To date, many methods are available for labor induction with the pharmaceutical and mechanical methods being the commonest. The most common pharmaceutical agents used are prostaglandins, oxytocin, synthetic progesterone antagonists, and nitric oxide. Mechanical induction is carried out through using balloon catheters, hygroscopic dilators, artificial membrane rupture, or membrane stripping. Though pharmaceutical methods had largely replaced mechanical induction of labor, no consensus guidelines recommend their use. Studies from literature are still conflicting. However, it is generally agreed that the use of a combined approach with both pharmaceutical and mechanical methods of induction yields the best outcome. This article will review the different methods for labor induction, their effectiveness, and adverse events.
\end{abstract}

Keywords: Labor induction, Mechanical induction, Pharmaceutical induction

\section{INTRODUCTION}

Induction of labor is one of the most common interventional procedures that are carried out during perinatal period. It is currently a daily routine that is performed the majority of obstetricians. To date, it is estimated that about $20 \%$ of all women giving birth undergo induction of labor. ${ }^{1}$ Labor induction refers to the stimulation of uterine contraction by artificial methods before the onset of normal labor. Basically, induction is indicated in certain well-established medical conditions and sometimes in some non-medical situations. For instance, medical conditions necessitating induction of labor include preeclampsia, eclampsia, premature rupture of membranes, gestational hypertension, gestational diabetes, profound fetal growth retardation, and post-term pregnancy. ${ }^{2}$ The principle of labor induction in these conditions is that the continuation of pregnancy is hazardous and riskier than termination. Living in a rural area far from maternal healthcare hospital exemplifies one of the non-medical situations that may require induction of labor. In contrast, induction of labor is contraindicated in a number of conditions such as placenta previa, transverse fetal position, active genital infection, history of myomectomy, umbilical cord 
prolapse, and gestational age below 39 weeks (or no evidence of lung maturity). ${ }^{3}$

Giving the increasing numbers of pregnant females with immature cervical findings, induction of labor became more preferable over non-interventional approaches. ${ }^{4}$ Despite the increasing popularity and usage of induction in labor, the effective method for this induction remains elusive. The main available management approaches for induction of labor are pharmaceutical and mechanical methods. Each of these methods can be used alone or combination of both to facilitate labor and reduce the need for caesarean section during deliveries. Pharmaceutical induction of labor comprises the use of medications such as oxytocin, prostaglandins (e.g. prostaglandin E2 or prostaglandin E1 analogue), progesterone receptor antagonists, or nitric oxide, whereas in mechanical induction, obstetricians use balloon catheters for stimulation of uterine contraction. ${ }^{5}$ The aim of this article is to review the effectiveness of pharmaceutical and mechanical methods for labor induction.

\section{PHARMACEUTICAL INDUCTION OF LABOR}

Pharmaceutical induction of labor has been used by obstetricians for many years. Many agents have been developed and studied for stimulation of uterine contractions before the onset of spontaneous contractions in normal labor. Ideally, the best pharmaceutical agent for labor induction should be available, effective, efficient, rapidly acting, cheap, and safe. Oxytocin, prostaglandins, progesterone receptor antagonists, and nitric oxide were the most common agents used for this purpose5. Induction of labor is carried out in two steps: cervical ripening and induction of delivery. Pharmaceutical agents are generally used for those two steps. This section will review the four common pharmaceutical medication used for labor induction.

\section{Oxytocin}

Oxytocin is one of the most common and most potent agents used for labor induction. Oxytocin is a hormone that is endogenously released during pregnancy and increases notably during delivery. At the end of pregnancy, the uterus expresses large numbers of oxytocin receptor for preparation of labor. When labor is due, oxytocin is naturally excreted to stimulate uterine contractions and initiate labor. As oxytocin mechanisms were discovered many decades ago, it has been used for labor induction since years6. Although preferred to be used during the induction phase, it is beneficial for use during both pre-induction cervical ripening phase and induction phase.

The mechanism of action of oxytocin during the preinduction phase remains unclear. Oxytocin is not known to act directly on the cervix. However, studies proved that the use of oxytocin during pre-induction of labor had better outcomes than using it only during induction phase. The main mechanism of oxytocin in labor induction is through acting on G-protein-coupled receptors on the surface of endometrial smooth muscles, thus increasing calcium concentration intracellularly and subsequently resulting in muscle contraction.

For labor induction, Oxytocin is given intravenously with a starting dose of $1-2 \mathrm{mU} / \mathrm{min}$ and increased gradually by 1-6 mU/min every 15-40 minutes. The main side effects of oxytocin use are induction failure, uterine tachysystole, and uterine rupture. Despite being rare, some of them are dangerous complications that should be considered. ${ }^{6,7}$

\section{Prostaglandins}

Many forms of prostaglandins are used for labor induction. The most common of them are prostaglandin E2 (dinoprostone) and prostaglandin E1 analogue (minoprostol). Prostaglandins are a group of physiologically active lipid compounds that are secreted in various tissues in human body. They act on many receptor types and therefore possess many actions according to the receptor acted upon. In labor, the prostaglandins mechanism of action includes a local reaction at uterine cervix and a second effect on uterine wall contractions. ${ }^{8}$ Local action on uterine cervix comprises secretion of collagenase, collagen degradation, and consequently cervical dilatation, softening, and ripening. They also act on uterine endometrium stimulation smooth muscle contractions during the second phase of labor induction. ${ }^{9}$

The main side effects of prostaglandins result from their action on various receptors all over the body. Common adverse events include nausea, vomiting, fever, and transient hypotension. Synthetic prostaglandins E2 are available as intracervical gel, vaginal suppositories, and controlled-released hydrogel pessary. Prostaglandin E1 analogue (minoprostol) is another synthetic prostaglandin that is available in oral, vaginal, and sublingual forms. Small doses of 50 micrograms are often used for labor induction. ${ }^{10}$

\section{Progesterone receptor antagonists}

Progesterone is a natural endogenously-released hormone that is secreted all through pregnancy and decreases significantly during labor. Progesterone main function is stabilization of pregnancy and thus it inhibits uterine smooth muscle contraction. It is also essential for maintenance of the structural integrity of the uterine cervix. When normal labor begins, a rapid drop of progesterone level takes place in order to release the uterine inhibition. Therefore, progesterone receptor antagonists (e.g. mifepristone) were developed for labor induction. The mechanism of action of mifepristone is through competitive inhibition of progesterone receptors. ${ }^{11}$ Mifepristone also act as an anti- 
glucocorticoid drug and thus it is contraindicated in patients who had been on long-term corticosteroid therapy (to avoid sudden corticosteroid withdrawal) and in patients with history of hemorrhagic disorders. Mifepristone is available in oral forms. It can be used alone or in combination with prostaglandins. Mifepristone was shown to have success rates of $76 \%$ versus $36 \%$ placebo. ${ }^{11}$ One of the heads to head studies comparing mifepristone with misoprostol and luminaria with misoprostol reported a significant reduction of delivery time among the patient's group who used mifepristone and misoprostol (10 hours and 16 hours in first and second group, respectively). ${ }^{12}$

\section{Nitric Oxide (NO)}

Nitric oxide (NO) is one of the free radicals released in the human body due to the action of nitric oxide synthetase on different compounds. In female reproductive system, nitric oxide is released from both the placenta and the cervix. Nitric oxide stimulates cervical smooth muscle relaxation through activating calcium efflux and thus it aids cervical ripening in preinduction phase. ${ }^{13}$

The main side effects of nitric oxide are headache and palpitation. Nitric oxide is available in isosorbide mononitrate given intravaginally in a dose of $40-80 \mathrm{mg}$. Data are still inconstant about the effectiveness of nitric oxide in labor induction. Some reports stated that there was no difference between the nitric oxide use and placebo as regards the delivery time, whereas others reported a significant reduction in delivery time in comparison to placebo. ${ }^{14,15}$

\section{MECHANICAL INDUCTION OF LABOR}

Mechanical methods for labor induction are older than pharmaceutical methods. They had been used for many decades and are still used either alone or, more commonly, in combination with pharmaceutical agents. The basis of mechanical induction of labor is to introduce various types of instruments (such as catheters, hygroscopic dilators, or luminaria tents) into the uterine cervix or the extra-amniotic space inside the uterine cavity to stimulate uterine contractions. ${ }^{16}$

Although mechanical induction became less commonly used since the introduction of various pharmaceutical agents, it is still used because of its advantages. Mechanical induction is simple, cheaper, and carries lower adverse effects when compared to pharmaceutical induction. However, they are contraindicated in particular conditions such as placenta previa, low-lying placenta, and active vaginal infection. The main adverse events are maternal discomfort and risk of infection. ${ }^{17}$

The mechanism of action of mechanical induction of labor comprises exerting local pressure on the wall of the uterine cervix and/or overstretching the lower segment of the uterine wall. This would consequently stimulate the uterus to secrete prostaglandins. Each instrument carries these mechanisms of action on a different way. ${ }^{18}$ For instance, the balloon catheters act mainly on the cervix. When the balloon is filled, it exerts a direct pressure effect on cervical wall leading to prostaglandin secretion and subsequent uterine contractions. ${ }^{19}$ Hygroscopic dilators, on the other hand, act through controlled mechanical pressure. After absorbing the local tissue fluids, the device expands inside the cervical canal exerting its pressure effect. ${ }^{20}$

The most common devices used for mechanical induction are Foley catheter, the Atad double-balloon catheter, and the luminaria tents. Catheters are introduced into the cervix to the cervical canal or intrauterine extra-amniotic space, balloons are then inflated, and traction may or may not be applied to the catheter. ${ }^{19}$ Laminaria tents are hydrophilic devices synthetized from sea-weed or hydrophilic materials. They are inserted inside the cervical canal and expand insidiously in size, due to their hydrophilic character, causing gradual stretching of the cervix. Another probably involved mechanism in promoting uterine contractions with these devices is stimulating the Ferguson reflex. ${ }^{17,18,20}$

Other less commonly used methods for mechanical induction of labor include digital sweeping or stripping of the membranes and artificial rupture of membranes. Digital membrane stripping is carried out by finger movement inside the cervix to separate cervical wall and fetal membranes. This stimulates prostaglandin release and consequent uterine contraction. ${ }^{21}$ Artificial rupture of membranes (or amniotomy) involves introduction of a sterile plastic hhok into the vagina and cervix to intentionally rupture the fetal membranes. When the amniotic fluid is released to the vagina, prostaglandin secretion and uterine contractions evolve facilitating labor. $^{22}$

\section{PHARMACEUTICAL VERSUS MECHANICAL INDUCTION OF LABOR}

Although pharmaceutical labor induction had largely replaced mechanical induction, the mechanical indication is not obselete. ${ }^{23}$ To date, many institutions still use pharmaceutical only, mechanical only, or a combination of both for labor induction. The choice depends largely on local institutional preferences, practical experience, instrumental availability, financial status, and available resources.

Many literature reports indicate that pharmaceutical methods for labor induction are superior to mechanical induction. Prostaglandins are the most widely used pharmaceutical agent for labor induction. Prostaglandins were superior to placebo in many studies, and superior to mechanical induction in others $(7 \%$ and $29 \%$ did not achieve delivery after 24 hours). ${ }^{24}$ However, using a Foley catheter for labor induction was shown to be 
superior to dinoprostine in one of the studies $(0 \%$ versus $5 \%$ of deliveries failed in the first 24 hours among mechanical and dinoprostine groups, respectively). ${ }^{1}$ Mechanical methods when compared to placebo showed significant reduction on delivery time (31\% versus $23 \%$ among mechanical induction and placebo, respectively). ${ }^{17}$

Intracervical prostaglandins and mechanical methods for labor induction showed comparable results among literature. However, mechanical induction was associated with lower risk of fetal complications. ${ }^{25}$ Similarly, no significant difference was noted between the effect of mechanical induction and both oral and vaginal misoprostol as regards the efficiency of labor induction within 24 hours. $^{26}$ Mechanical induction and oxytocin had also comparable results. However, the adverse events among the mechanical induction group were higher. ${ }^{16}$

Though results are conflicting as regards the efficacy of mechanical versus pharmaceutical methods of induction, it is agreed that combination of both results yielded the best outcome. ${ }^{27-29}$

\section{CONCLUSION}

Pharmaceutical and mechanical methods are effective for labor induction. The most common pharmaceutical agents used are prostaglandins, oxytocin, synthetic progesterone antagonists, and nitric oxide. Mechanical induction is carried out through using balloon catheters, hygroscopic dilators, artificial membrane rupture, or membrane stripping. Though pharmaceutical methods had largely replaced mechanical induction of labor, no consensus guidelines recommend their use. Studies from literature are still conflicting. However, it is generally agreed that the use of a combined approach with both pharmaceutical and mechanical methods of induction yields the best outcome.

Funding: No funding sources Conflict of interest: None declared

Ethical approval: Not Required

\section{REFERENCES}

1. Levine LD, Downes KL, Elovitz MA, Parry S, Sammel MD, Srinivas SK. Mechanical and Pharmacologic Methods of Labor Induction: A Randomized Controlled Trial. In: Obstetrics and Gynecology. Vol 128. ; 2016:1357-1364.

2. Bonsack CF, Lathrop A, Blackburn M. Induction of Labor: Update and Review. J Midwifery Womens Health. 2014;59(6):606-615.

3. Induction L. ACOG Committee Opinion no. 597: Committee on Obstetric Practice: Labor induction or augmentation and autism. Obstet Gynecol. 2014;123(5):1140-1142.

4. L. S. Induction of labor. Monatsschr Kinderheilkd. 2014;162(1):75-84.
5. Gilstrop M, Sciscione A. Induction of laborPharmacology methods. Semin Perinatol. 2015;39(6):463-465.

6. Alfirevic Z, Kelly AJ, Dowswell T. Intravenous oxytocin alone for cervical ripening and induction of labour. Cochrane Database Syst Rev. 2009;(4).

7. Budden A, Henry A, Heatley E. Oxytocin infusion regimens for induction of labour. In: Cochrane Database of Systematic Reviews. Vol 122. ; 2012:163.

8. Løkkegaard E, Lundstrøm M, Kjær MM, Christensen IJ, Pedersen HB, Nyholm H. Prospective multicentre randomised trial comparing induction of labour with a double-balloon catheter versus dinoprostone. J Obstet Gynaecol (Lahore). 2015;35(8):797-802.

9. Chyu JK, Strassner HT. Prostaglandin E2for cervical ripening: A randomized comparison of Cervidil versus Prepidil. Am J Obstet Gynecol. 1997;177(3):606-611.

10. Ferguson JE, Head BH, Frank FH, et al. Misoprostol versus low-dose oxytocin for cervical ripening: A prospective, randomized, double-masked trial. In: American Journal of Obstetrics and Gynecology. Vol 187. ; 2002:273-280.

11. Hapangama D, Neilson JP. Mifepristone for induction of labour. Cochrane Database Syst Rev. 2009;(3).

12. Prairie BA, Lauria MR, Kapp N, MacKenzie T, Baker ER, George KE. Mifepristone versus laminaria: a randomized controlled trial of cervical ripening in midtrimester termination. Contraception. 2007;76(5):383-388.

13. Ghosh A, Lattey KR, Kelly AJ. Nitric oxide donors for cervical ripening and induction of labour. Cochrane Database Syst Rev. 2016;2016(12).

14. Bullarbo M, Orrskog ME, Andersch B, Granström L, Norström A, Ekerhovd E. Outpatient vaginal administration of the nitric oxide donor isosorbide mononitrate for cervical ripening and labor induction postterm: a randomized controlled study. Am J Obstet Gynecol. 2007;196(1).

15. Kelly Anthony J, Munson C, Minden L. Nitric oxide donors for cervical ripening and induction of labour. Cochrane Database Syst Rev. 2011;(6).

16. Jozwiak M, Bloemenkamp KWM, Kelly AJ, Mol BWJ, Irion O, Boulvain M. Mechanical methods for induction of labour. Cochrane database Syst Rev. 2012;(3):CD001233.

17. McCarthy FP, Kenny LC. Induction of labour. Obstet Gynaecol Reprod Med. 2014;24(1):9-15.

18. Maroto Martín MT, Revelles Paniza L, Ruiz Durán S, Copado Salido S, Barranco Armenteros M, Puertas Prieto A. Mechanical methods for labour induction. J Perinat Med. 2015;43.

19. Ballarat Health Services. Induction of labour: Transcervical Catheter. Induction labour transcervical Catheter. 2011;7(3):481-509.

20. Arshad AH, Zainuddin AA, Ghani NAA, Ali A. The efficiency of laminaria as an adjunct to induction of 
labour with prostin: A randomised controlled trial. BJOG An Int J Obstet Gynaecol. 2016;123:156.

21. Emarah M. Stripping of Membranes in Induction of Labour. Int $\mathrm{J}$ Recent Adv Multidiscip Res. 2015;02(10):875-878.

22. Bricker L, Luckas M. Amniotomy alone for induction of labour. In: Cochrane Database of Systematic Reviews. 2000.

23. Goetzl L. Methods of Cervical Ripening and Labor Induction. Clin Obstet Gynecol. 2014;57(2):377-390.

24. Henry A, Madan A, Reid R, et al. Outpatient Foley catheter versus inpatient prostaglandin E2 gel for induction of labour: A randomised trial. BMC Pregnancy Childbirth. 2013;13.

25. Boulvain $M$, Kelly AJ, Irion O. Intracervical prostaglandins for induction of labour. Cochrane Database Syst Rev. 2008;(1).

26. Mozurkewich EL, Chilimigras JL, Berman DR, et al. Methods of induction of labour: A systematic review. BMC Pregnancy Childbirth. 2011;11. doi:10.1186/1471-2393-11-84

27. Carbone JF, Tuuli MG, Fogertey PJ, Roehl KA, MacOnes GA. Combination of foley bulb and vaginal misoprostol compared with vaginal misoprostol alone for cervical ripening and labor induction: A randomized controlled trial. Obstet Gynecol. 2013;121(2 PART 1):247-252.

28. Al-Ibraheemi Z, Brustman L, Bimson BE, Porat N, Rosenn B. Misoprostol With Foley Bulb Compared With Misoprostol Alone for Cervical Ripening: A Randomized Controlled Trial. Obstet Gynecol. 2018;131(1):23-29.

29. Chung JH, Huang WH, Rumney PJ, Garite TJ, Nageotte MP. A prospective randomized controlled trial that compared misoprostol, Foley catheter, and combination misoprostol-Foley catheter for labor induction. Am J Obstet Gynecol. 2003;189(4):10311035.

Cite this article as: Alsaif M, Helmy N, Almuallem F, Almagboul S, Almtrafi H, Matouq B, et al.

Pharmaceutical versus mechanical induction of labor. Int J Reprod Contracept Obstet Gynecol 2018;7:4325-9. 